\title{
Heart rate variability is enhanced in controls but not maladaptive perfectionists during brief mindfulness meditation following stress-induction: A stratified-randomized trial
}

\author{
Muhammad Abid Azam ${ }^{\text {a }}$, Joel Katz ${ }^{\mathrm{a}, \mathrm{b}}$, Samantha R. Fashler ${ }^{\mathrm{b}}$, Tina Changoor ${ }^{\mathrm{a}}$, Saam Azargive ${ }^{\mathrm{a}}$, Paul Ritvo ${ }^{\mathrm{a}, \mathrm{b}, *}$ \\ a School of Kinesiology and Health Science York University, Toronto, Ontario M3J 1P3, Canada \\ ${ }^{\mathrm{b}}$ Department of Psychology, York University, Toronto, Ontario M3J 1P3, Canada
}

\section{A R T I C L E I N F O}

\section{Article history:}

Received 27 March 2015

Received in revised form 16 June 2015

Accepted 17 June 2015

Available online 25 June 2015

\section{Keywords:}

Heart rate variability

Mindfulness meditation

Stress

Maladaptive perfectionism

Attention

\begin{abstract}
A B S T R A C T
Heart rate variability (HRV) is a vagal nerve-mediated biomarker of cardiac function used to investigate chronic illness, psychopathology, stress and, more recently, attention-regulation processes such as meditation. This study investigated HRV in relation to maladaptive perfectionism, a stress-related personality factor, and mindfulness meditation, a stress coping practice expected to elevate HRV, and thereby promote relaxation. Maladaptive perfectionists $(n=21)$ and Controls $(n=39)$ were exposed to a lab-based assessment in which HRV was measured during (1) a 5-minute baseline resting phase, (2) a 5-minute cognitive stress-induction phase, and (3) a post-stress phase. In the post-stress phase, participants were randomly assigned to a 10-minute audioinstructed mindfulness meditation condition or a 10-minute rest condition with audio-description of mindfulness meditation. Analyses revealed a significant elevation in HRV during meditation for Controls but not for Perfectionists. These results suggest that mindfulness meditation promotes relaxation following cognitive stress and that the perfectionist personality hinders relaxation possibly because of decreased cardiac vagal tone. The results are discussed in the context of developing psychophysiological models to advance therapeutic interventions for distressed populations.
\end{abstract}

\section{Introduction}

Heart rate variability (HRV) is the beat-to-beat variation in heart rate (HR) or the inter-beat interval (i.e. heart period) and is a widely used biomarker for the coordinated activity of the sympathetic nervous system (SNS) and parasympathetic nervous system (PNS; Cacioppo et al., 2007; Karim et al., 2011) Psychological stress (i.e. problem solving, decision-making, worrying) leads to cardiovascular activation via the autonomic nervous system (ANS; Fabes and Eisenberg, 1997; Taelman et al., 2009). A typical cardiac stress response involves SNS activation wherein sympathetic nerve fibers release the excitatory neurotransmitters epinephrine and norepinephrine onto the heart's sinoatrial (SA) node to accelerate HR (Cacioppo et al., 2007; Karim et al., 2011; Thayer et al., 2012). In the aftermath, return to cardiac resting state requires parasympathetic influence to be instated through vagal nerve activation and its associated release of acetylcholine-a neurotransmitter that inhibits the SA node and decelerates HR. In contrast to stressful states, more restful and self-regulated states are typically marked by increased HRV, largely attributed to respiration-based (parasympathetic) HR control, particularly as slower respiration stimulates vagus nerve activity (Grossman and Taylor, 2007; Porges and Byrne, 1992). Thus,

\footnotetext{
* Corresponding author at: 4700 Keele Street, Toronto, Ontario M3J 1P3, Canada. E-mail addresses: pritvo@yorku.ca, abidazam@yorku.ca (P. Ritvo).
}

as an indicator of autonomic cardiac activity, the variation in HRV is used as an index of continuous and real-time changes in parasympathetic function at rest and under specific conditions (Allen et al., 2007; Force, 1996).

Insufficient parasympathetic function (corresponding with reduced HRV) can result in difficulties in reaching restful and relaxed states post-stress, while extended autonomic activity can accumulate as cardiovascular disease risks (Haensel et al., 2008; Kemp et al., 2012) and as stable or chronic anxiety-depressive conditions (Brosschot et al., 2006). Conversely, a growing literature associates increased HRV with enhanced attention-regulation (Chida and Steptoe, 2010; Segerstrom and Nes, 2007; Thayer et al., 2009) and with the practice of various forms of meditation (Burg and Wolf, 2012; Krygier et al., 2013; Phongsuphap et al., 2008). Collectively, the evidence suggests that variations in relaxation capabilities after stressful conditions can be explained by the effective practice of attention regulation techniques.

A relevant yet unexplored stress-related factor that can potentially hinder the relaxation process is maladaptive perfectionism. Maladaptive perfectionism is a personality construct characterized by a persistent striving for unrealistic personal standards, an excessive concern over mistakes, and an attentional bias for failure (Hewitt and Flett, 1991; Lo and Abbott, 2013). Excessive perfectionistic thinking is consistently associated with chronic stress (Ashby et al., 2012; Flett et al., 1998; Pirbaglou et al., 2013), greater worry and rumination levels 
(Harris et al., 2008), and psychiatric diagnoses (Antony et al., 1998; Chang and Sanna, 2001; Saboonchi and Lundh, 1997).

Perseverative cognitions-characterized as worry and ruminationhave been suggested to produce health detriments including frequently prolonged elevations in HR and decreases in HRV (Brosschot et al., 2006; Brosschot, 2010). These suggestions are supported by both short term and long term studies on the cardiac response to stress and worry (Brosschot et al., 2007; Brosschot and Thayer, 2003; Glynn, 2002; Pieper et al., 2007, 2010; Verkuil et al., 2009). For example, in a study of normal populations assessed by ambulatory monitoring, HRV decreased during periods when participants reported that they had been worrying (Brosschot et al., 2007). Further, Papousek et al. (2011) studied HR responses to a task that provided performance feedback manipulated to be inconsistent with participants' self-concept. They found evidence of delayed psychophysiological recovery which supported the 'perseverative cognition' model of detriments from negative cognitive representations of stressful conditions (Papousek et al., 2011). Taken together, these findings support the hypothesis that Perfectionists, who are known to engage in a higher frequency of perseverative cognitions, will demonstrate decreased HRV during and after a stress-induction that activates cognitive schemas pertaining to perceived failure and unrealistic performance standards.

Given this hypothesis, it is important to explore stress-regulation practices conducive to cardiac-based relaxation evident through increases in HRV. Recent theoretical and empirical developments suggest that perfectionism and perseverative cognitions can be reduced by cognitive-behavioral therapy and mindfulness meditation (Delgado et al., 2010; Masuda and Tully, 2012; Nyklíček et al., 2013). A recent randomized controlled-trial adopting both approaches to treat maladaptive perfectionists revealed significant reductions in anxiety sensitivity and negative automatic thoughts (Radhu et al., 2012a; Guglietti et al., 2013). An additional trial has shown that post-intervention improvements may be seen in Perfectionists cortical inhibition-a neurophysiological mechanism associated with therapy-related improvements and mindfulness meditation (Radhu et al., 2012b). Given the importance of attention regulation and mindfulness to current psychotherapeutic approaches, more evidence is needed to support the hypothesis that mindfulness training can assist individuals in regulating cardiac stress responses.

Mindfulness meditation has received significant interest in health psychology, neurophysiology, and, more recently, psychophysiology. Evidence indicates that mindfulness meditation helps regulate psychological distress through physiological relaxation processes (Argus and Thompson, 2007; Short and Mazmanian, 2013). Mindfulness is conceptualized as a family of techniques that emphasize purposeful and nonjudgmental awareness of present moment experiences i.e. cognitions, emotions, physical sensations, and external stimuli (Didonna, 2009). Putatively, seated mindfulness meditation generates a relaxation effect through a combination of focal attention on one's breathing sensations and open-monitoring of immediate experiences (Didonna, 2009), processes that serve to orient one to the present time-frame in contrast to past experiences or future outcomes (Grossman et al., 2004).

Studies have found mindfulness practices associated with positive changes in cognitive function (Chiesa et al., 2011), brain regions associated with attention (Lazar et al., 2006) and emotion regulation (Lutz et al., 2008), and reductions in chronic stress (Mankus et al., 2013; Ritvo et al., 2013). Furthermore, HRV has been shown to increase during brief mindfulness meditation practice (Burg and Wolf, 2012; Ditto et al., 2006; Tang et al., 2009) as well as after engagement in long-term meditation retreats (Delgado-pastor et al., 2013; Krygier et al., 2013). Given that parasympathetic HR control is primarily established by respiratorylinked variations modulated by the vagus nerve (Allen et al., 2007; Force, 1996), and that respiration (via awareness of breathing) is central to meditation, HRV is posited as a physiological correlate of mindful states, while respiration is an important confounding variable to control (Allen et al. 2007).
The present study assessed a sample of maladaptive perfectionists and a control group on stress reactivity and post-stress relaxation. A three-phase protocol involved HRV measurement (primary outcome) during a baseline rest phase, a stress-induction phase, and a poststress phase in which participants were randomized to a brief audioguided mindfulness meditation condition or a resting condition consisting of an audio description of mindfulness meditation. The following hypotheses were tested:

1. Stress phase HRV would be lower than baseline HRV for all participants. This effect was expected to be greater in Perfectionists compared to Controls.

2. Control participants assigned to the mindfulness meditation condition, but not Perfectionists, would exhibit increases in HRV from Phase 2 (stress phase) to Phase 3 (meditation).

\section{Materials \& methods}

\subsection{Participants}

This study was conducted at a large public university and recruited undergraduate students of all years of study and majors through an online system of research participation which grants course credit.

Exclusion criteria included a history or current diagnosis of any anxiety disorder and/or major depressive disorder and cardiovascular disease (hypertension, coronary artery disease, and arrhythmias) as these conditions are known to involve ANS dysfunction (Chalmers et al., 2014; Haensel et al., 2008; Kemp et al., 2012; Marano et al., 2009; Miu et al., 2009). Participants were excluded if they had a history of practicing mindfulness meditation or even minimal exposure to the practice (>60 $\mathrm{min})$.

\subsection{Sample size estimation}

Based on a review of the literature, changes in HRV during mindfulness meditation have been reported to range between medium (Burg and Wolf, 2012; Takahashi et al., 2005) and large effect sizes (Krygier et al., 2013). Given $\alpha=.05$ and the employment of multivariate statistical tests to study within-subject HRV changes during meditation, it was estimated that a total sample size of 40 participants would provide acceptable power (0.80) to assess a medium effect size (partial eta squared $>0.06)$ and excellent power $(0.95)$ for detecting a large effect size (partial eta squared $>0.14$ ).

\subsection{Screening}

The Perfectionism Cognitions Inventory (PCI) assesses the frequency of automatic thoughts with perfectionist themes that highlight the discrepancy between one's current and ideal self (Flett et al., 2007; Flett et al., 1998; Flett et al., 2011). Participants are asked to indicate how often they experienced perfectionistic thoughts (e.g. "I should never make the same mistake twice" and "I must be efficient at all times") in the previous week on a 5-point Likert scale. The PCI has demonstrated adequate validity and reliability and correlational analyses have revealed strong associations with trait perfectionism, psychological distress, and depressive-anxious symptoms (Flett et al., 2007; Flett et al., 2011; Pirbaglou et al., 2013). Furthermore, there has been no gender difference in mean PCI scores found (Flett et al., 1998).

The current study utilized the procedure used in two previous randomized-controlled trials (Arpin-Cribbie et al., 2008; Radhu et al., $2012 \mathrm{~b}$ ) to screen for maladaptive perfectionism. The Perfectionist group consisted of participants with PCI scores falling at or above 66, which represents the value lying one standard deviation above the established mean of the PCI (Arpin-Cribbie et al., 2008). The Control group consisted of all eligible participants whose scores fell below the cut-off of 66. The alpha coefficient value for the PCI in this study 
indicated excellent internal consistency ( $\alpha=.96$ ). Additional perfectionism measures were obtained using the Multidimensional Perfectionism Scale (MPS), containing factors of self-oriented and socially prescribed perfectionism (Hewitt et al., 1991.

\subsection{Procedure}

All participants provided written informed consent upon arriving at the laboratory session. All study procedures were approved by the Human Participants Review Subcommittee at the university where the study was conducted. Upon arrival at the lab, and after obtaining informed written consent to participate, all participants completed computer-based self-report questionnaires (this manuscript reports only results from the perfectionism inventories). Following this, all participants were first measured during a baseline rest phase, followed by a stress-induction phase, and post-stress conditions. Post-stress condition allocation was determined by the experimenter immediately following the stress-induction using a previously prepared randomization schedule (www.randomization.com) to a mindfulness meditation or resting (control) condition. No indication was provided to the participants as to whether they qualified as Perfectionists or Controls, or to the purpose of the stress-induction and post-stress conditions.

In the baseline rest phase, participants were asked to remain seated in a relaxed and upright manner for 5 min while thinking freely with their eyes open. They were instructed not to make any sudden movements, keep their gaze in the same direction, and remain silent.

For stress-induction, in a computer-based pattern recognition task (PRT), participants were asked to study 4 alphanumeric characters presented at the top of the screen for $9 \mathrm{~s}$ and determine the pattern that they follow (Fig. 1). After $9 \mathrm{~s}$, a 5 th character was shown and the text "True or False?" appeared in the middle of the screen. Participants were instructed to respond with the following key as quickly as possible "True" ( $\leftarrow$ key) if they believed the 5 th character followed the pattern or "False" ( $\rightarrow$ key) if it did not. Immediately after the response, the text "Right Answer" or "Wrong Answer" was presented at the bottom left or bottom right of the screen, respectively for $3 \mathrm{~s}$. Numbers indicating total "Correct [x]" (bottom right) and "Incorrect [y]" (bottom left) answers totaled to the current trial remained on the screen.

The alphanumeric characters were designed to appear as if they followed simple or complex patterns, however, none of the problem sets followed a specific pattern (see Appendix A for characters used). The "Right Answer" and "Wrong Answer" presentation was configured using a pre-determined random order so that each would be presented 11 times throughout the 22 trials. Participants were informed that the PRT "assesses one's capacity for abstract problem solving" and that for each trial they had to "respond as quickly as possible". The average

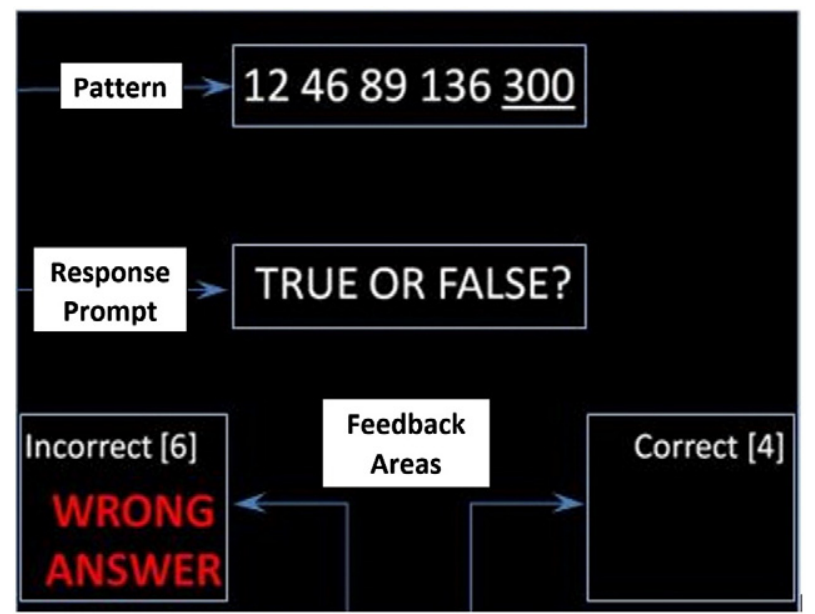

Fig. 1. Pattern recognition task time to task completion was 5 min and $15 \mathrm{~s}$. After task completion, a manipulation check was performed in which participants were asked to rate their performance of the PRT by selecting one of five possible options, "poor", "below average”, “average", “above average", or "excellent".

For the post-stress mindfulness meditation condition participants were asked to remain seated in a relaxed and upright manner with eyes closed. A 10 minute audio recording was played featuring mindfulness instructions emphasizing attention to breathing sensations and a reorientation to breathing sensations once there was awareness of thoughts, emotions, bodily sensations, and/or external stimuli (Ritvo et al., 2013). The instructions were recorded by a clinical psychologist and experienced MM instructor.

In the post-stress rest condition, participants were seated identically as in the MM condition (including eyes closed), and were played an audio description of historical and scientific information on MM by the same instructor for $10 \mathrm{~min}$. This recording did not deliver any instruction on how to practice mindfulness meditation, participants were asked to simply rest while the recording played.

At the end of the final phase, participants were debriefed and informed that the PRT involved unsolvable problem sets and feedback was administered for stress-induction purposes.

\subsection{Heart rate variability data collection \& analyses}

Electrocardiogram (ECG) recordings were collected using ADInstruments' (ADI) PowerLab 4-channel data acquisition system (Colorado Springs, United States), which utilizes 2 adhesive electrodes applied to the chest and a ground electrode on the ankle. Midway through the study's data collection period, an ADI respiratory belttransducer was acquired to obtain respiratory measures. The belt was securely placed across a participant's midsection and acquired respiration rate data (Allen et al., 2007).

LabChart Pro software by ADI is integrated with the PowerLab unit and was used to calculate frequency-based HRV metrics (Allen et al., 2007). Frequency-based metrics are of greater interest due to their associations with the modulation of the ANS; changes in the power of frequency bands better represents the sympatho-vagal response compared to time-domain metrics (Force, 1996). Three primary spectral components are determined in a spectrum calculated from ECG recordings of 2-5 min; very low frequency (VLF; $0.003-0.04 \mathrm{~Hz}$ ), low frequency (LF; 0.04-0.15 Hz), and high frequency (HF; 0.15-0.4 Hz). The power of the HF band is extensively used as an index of RSA (Force, 1996). This band captures HR fluctuations attributed to parasympathetic (vagal) function (with power computed as units of milliseconds ${ }^{2}$ ).

The 10-minute post-stress recordings were divided into two 5-minute segments in order to; a) to keep the time-length of the ECG recordings used to calculate HRV consistent (i.e. $5 \mathrm{~min}$ for baseline, stress-induction, and two post-stress phases) and b) to allow for an additional time-point to assess response to meditation instruction.

\subsection{Statistical analyses}

All data was examined for normality prior to statistical testing. Comparisons of demographic and psychometric data between Perfectionists and Control groups were conducted using independent t-tests and chi-square tests of independence (Table 1). Respiration rate, as suggested by Houtveen et al. (2002), was analyzed by 3-way analysis of variance (ANOVA) with Group (Perfectionists vs. Control), Condition (meditation vs. rest) and Phase (baseline, stress, post-stress 1-5 min, post-stress 6-10 $\mathrm{min}$ ) as factors.

The HRV data was log transformed to neutralize positive skews. Analysis was conducted using $2 \times 2 \times 4$ between-subjects ANOVA with Group (Perfectionists vs. Control) and Condition (meditation vs. rest) as the between-subjects factors, and Phase (baseline, stress, poststress $1-5$ minute period, and post-stress $6-10$ minute period) as the 
Table 1

Demographic, psychometric, heart rate, and respiration data.

\begin{tabular}{|c|c|c|c|}
\hline \multirow[t]{2}{*}{ Measure } & Perfectionists & Controls & \multirow[t]{2}{*}{ Tests of significance } \\
\hline & $(n=21)$ & $(n=39)$ & \\
\hline Age (years) $(S D)$ & $22.05(1.57)$ & $20.62(.82)$ & $t_{(58)}=.89, \mathrm{p}=.38$ \\
\hline Gender n (\%) & & & $\chi^{2}(1)=.21, \mathrm{p}=.64$ \\
\hline Male & $10(47.62)$ & $21(53.85)$ & \\
\hline Female & $11(52.38)$ & $18(46.15)$ & \\
\hline Education n (\%) & & & $\chi^{2}(3)=7.63, \mathrm{p}=.05$ \\
\hline Bachelor's degree & $1(4.76)$ & $1(4.76)$ & \\
\hline College & $4(19.04)$ & $2(9.52)$ & \\
\hline High school & $14(66.67)$ & $36(92.3)$ & \\
\hline Master's degree & $2(9.52)$ & $0(0)$ & \\
\hline Weekly exercise n (\%) & & & $\chi^{2}(2)=.45, \mathrm{p}=.80$ \\
\hline Often & $11(52.38)$ & $17(43.59)$ & \\
\hline Sometimes & $8(38.10)$ & $17(43.59)$ & \\
\hline Rarely/never & $2(9.52)$ & $5(12.82)$ & \\
\hline \multicolumn{4}{|l|}{ Perfectionism $M(S D)$} \\
\hline $\mathrm{PCl}^{\mathrm{a}}$ & $73.8(6.79)$ & $39.13(15.72)$ & $t_{(58)}=11.87, \mathrm{p}<.000$ \\
\hline SOP & $75.43(13.43)$ & $61.67(15.06)$ & $t_{(58)}=3.50, \mathrm{p}=.001$ \\
\hline SPP & $63.48(11.07)$ & 49.90 (12.07) & $t_{(58)}=4.28, \mathrm{p}<.000$ \\
\hline \multicolumn{3}{|c|}{ Performance rating $\mathrm{n}(\%)^{\mathrm{b}}$} & $\chi^{2}(3)=1.62, \mathrm{p}=.65$ \\
\hline Excellent & $0(0)$ & $0(0)$ & \\
\hline Above average & $0(0)$ & $2(5.1)$ & \\
\hline Average & $10(47.62)$ & $21(53.85)$ & \\
\hline Below average & $8(38.10)$ & $11(28.21)$ & \\
\hline Poor & $3(14.29)$ & $5(12.82)$ & \\
\hline Respiration CPM $(S D)^{\mathrm{c}}$ & & & $F_{(3,20)}=.04, \mathrm{p}=.94$ \\
\hline Rest & $15.73(2.87)$ & $15.75(2.42)$ & \\
\hline Stress & $19.92(2.25)$ & $20.08(5.33)$ & \\
\hline Post-stress meditation & $13.99(2.41)$ & $12.99(2.40)$ & \\
\hline Post-stress rest & $10.86(2.55)$ & $16.73(4.46)$ & \\
\hline Stress heart rate (BPM) & $76.32(8.11)$ & $79.61(8.06)$ & $t_{(58)}=-1.51, \mathrm{p}=.87$ \\
\hline
\end{tabular}

Note.

$M=$ Mean; $\mathrm{PCI}=$ Perfectionism Cognitions Inventory; SOP = Self-Oriented Perfectionism; SPP = Socially Prescribed Perfectionism (factor scores from Multidimensional Perfectionism Scale). $\mathrm{CPM}=$ Cycles per Minute. BPM = Beats per Minute.

a $t$-Test based on Levene's correction for unequal variances.

b Ratings obtained after stress-induction task.

c $n=23$ (Perfectionists $=8$; Controls $=15$ ).

within-subjects factor. The violation of the sphericity assumption was handled by conducting a multivariate ANOVA (MANOVA). Significant interaction effects were followed up with simple effects analysis and pairwise comparisons using a Bonferroni Type I error rate correction.

\section{Results}

\subsection{Recruitment and participant flow}

A total of 68 participants was recruited ( males $=36$; females $=32$ ). One participant (female, control) completed consent and questionnaires but withdrew from the study prior to phase 1 . Seven participants were excluded from the final analyses; 5 due to unanalyzable ECG data (signal noise), and 2 due to their disclosure (in the debriefing interview) that they had become aware of the deception in the PRT during the stress phase (Fig. 2). Table 1 displays characteristics of the 60 participants included in the final analyses based on stratification into Perfectionists or Control groups (See Fig. 2).

\subsection{Group characteristics}

Twenty-one participants were classified as Perfectionist, and 39 as Controls. Perfectionists were 52\% female, with a mean age of 22 $(\mathrm{SD}=1.57)$, and Controls were $53 \%$ male, with a mean age of 21 $(\mathrm{SD}=.82)$. No significant differences were found with respect to respiration rate or verbal performance ratings between groups (Table 1 ). Approximately 59\% of Control participants self-rated as performing "Average" or above on the PRT after stress-induction, while $52 \%$ of Perfectionists self-rated as performing "Below Average" or lower.

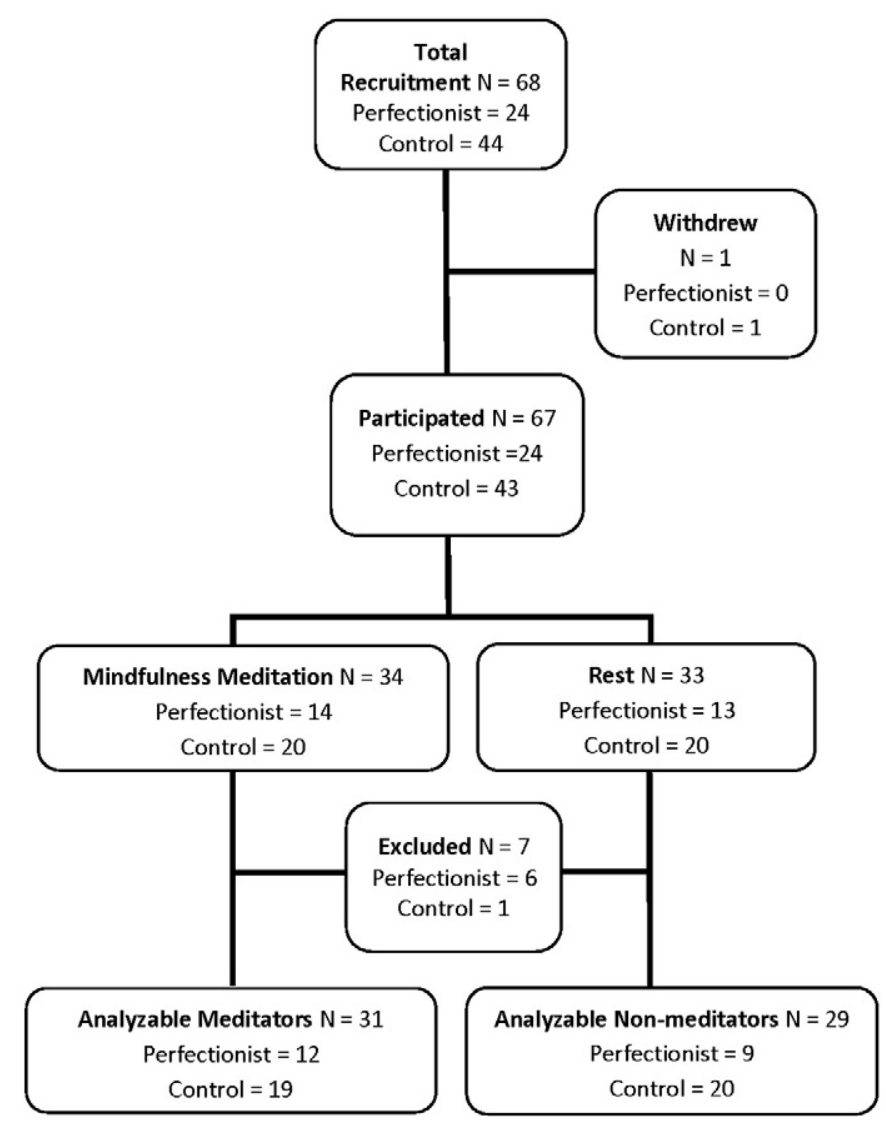

Fig. 2. Flow of participants through the study.

\subsection{Overall results}

For the initial ANOVA, Mauchly's test of sphericity was significant $\left(\chi^{2}(5)=.73, p=.005\right)$ and a MANOVA approach to results was taken. The MANOVA revealed a significant main effect of Phase $\left(\wedge=.25, F_{(3,54)}=6.09, \mathrm{p}=.001, \eta_{p}^{2}=.25\right)$, a significant Group $\times$ Phase interaction $\left(\wedge=.86, F_{(3,54)}=2.82, \mathrm{p}=.047\right.$, $\left.\eta_{p}^{2}=.14\right)$, and a significant Group $\times$ Condition $\times$ Phase interaction $\left(\wedge=.14, F_{(3,54)}=2.98, \mathrm{p}=.039 \eta_{p}^{2}=.14\right)$. All other main effects and interaction effects were not significant (all $\mathrm{p}>0.05$ ) (Fig. 3).

\subsection{Hypothesis 1: decreased HRV during stress}

The significant main effect of Phase was followed up with pairwise comparisons showing, as hypothesized, that mean HRV was lower during Phase 2 (stress) $(M=2.73$, SEM $=.05)$ compared to Phase 1 (baseline) $(M=2.87$, SEM $=.06)(\mathrm{p}=.005)$.

Next, stress HRV was evaluated by analyzing the Group $x$ Phase interaction. The simple effect of Group at the stress phase was not significant $\left(F_{(1,56)}=.12, \mathrm{p}=.73, \eta_{p}^{2}=.002\right)$. The simple effect of Phase within groups was significant for Controls $\left(\wedge=.37, F_{(3,54)}=10.63\right.$, $\left.\mathrm{p}<.000, \eta_{p}^{2}=.37\right)$ but not Perfectionists $\left(\wedge=.94, F_{(3,54)}=1.20\right.$, $\left.\mathrm{p}=.32, \eta_{p}^{2}=.06\right)$. Bonferroni-adjusted pairwise comparisons $(\mathrm{p}>.008)$ revealed a trend in Controls for HRV during the baseline rest phase $\left(M_{\text {rest }}=2.87, \mathrm{SEM}=.07\right)$ to be greater than that during the stress phase $\left(M_{\text {stress }}=2.72\right.$, SEM $\left.=.06\right)(\mathrm{p}=.009)$ (Table 2$)$.

\subsection{Hypothesis 2: increased HRV in controls during mindfulness}

Hypothesis 2 was evaluated by analyzing the Group $x$ Condition $\times$ Phase interaction. The simple effect of Phase for Controls 

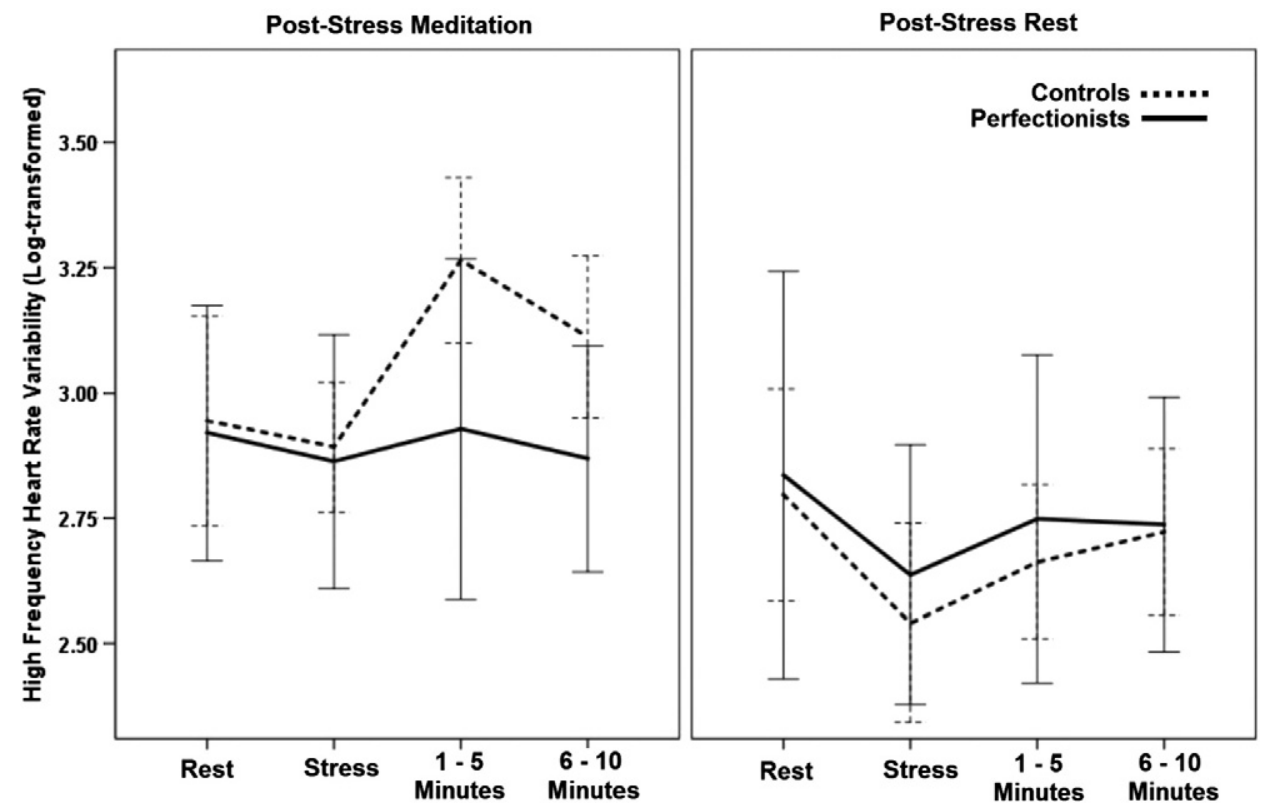

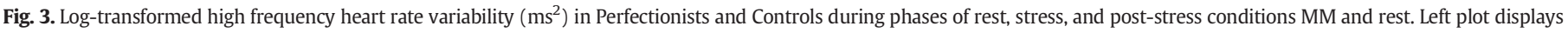

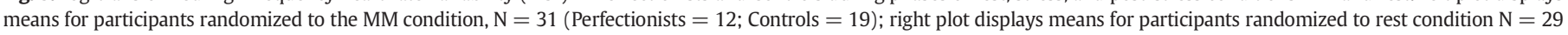
(Perfectionists $=9$; Controls $=20$ ). Bars represent standard errors.

in the meditation condition was significant $\left(\wedge=.50, F_{(3,54)}=17.96\right.$, $\mathrm{p}<.000, \eta_{p}^{2}=.50$ ). Follow-up pairwise comparisons showed that HRV in Controls was significantly greater during the first $5 \mathrm{~min}$ of meditation than during stress and it remained elevated at 6-10 min. In contrast, the simple effect of Phase for Perfectionists in the meditation condition was not significant $\left(\wedge=.98, F_{(3,54)}=.42, \mathrm{p}<.74, \eta_{p}^{2}=.02\right)$.

Lastly, HRV during post-stress was also evaluated by analyzing the Group $\times$ Phase $\times$ Condition interaction. The simple effects of Condition for Controls at the first $\left(F_{(1,56)}=22.57, \mathrm{p}<.000, \eta_{p}^{2}=.29\right)$ and second post-stress $\left(F_{(1,56)}=12.45, \mathrm{p}=.001, \eta_{p}^{2}=.18\right)$ phases were significant, indicating Controls showed greater HRV during meditation when compared to rest (Table 3). The simple effect of Condition for Perfectionists was not significant at either the first post-stress $\left(F_{(1,56)}=1.05, \mathrm{p}=.31\right.$, $\left.\eta_{p}^{2}=.02\right)$ or second post-stress $\left(F_{(1,56)}=.75, \mathrm{p}=.39, \eta_{p}^{2}=.01\right)$ phase.

Table 2

Means and SEM of HF-HRV during post-stress phases according to conditions within groups.

\begin{tabular}{|c|c|c|c|c|}
\hline \multirow[b]{3}{*}{ Phase } & \multicolumn{4}{|c|}{ Maladaptive perfectionists $(n=21)$} \\
\hline & \multicolumn{2}{|c|}{ MM condition $(n=12)$} & \multicolumn{2}{|c|}{ Rest condition $(n=9)$} \\
\hline & Mean & SEM & Mean & SEM \\
\hline Stress & 2.86 & .11 & 2.64 & .12 \\
\hline Post-stress (1-5 min) & 2.93 & .11 & 2.75 & .13 \\
\hline \multirow[t]{3}{*}{ Post-stress (6-10 min) } & 2.87 & .10 & 2.74 & .12 \\
\hline & \multicolumn{4}{|c|}{ Controls $(n=39)$} \\
\hline & \multicolumn{2}{|c|}{ MM condition $(n=19)$} & \multicolumn{2}{|c|}{ Rest condition $(n=20$} \\
\hline Phase & Mean & SEM & Mean & SEM \\
\hline Stress & 2.89 & .08 & 2.54 & .08 \\
\hline Post-stress (1-5 min) & $3.27^{* *}$ & .09 & 2.66 & .09 \\
\hline Post-stress (6-10 min) & $3.11^{*}$ & .08 & 2.72 & .08 \\
\hline
\end{tabular}

Note. Bonferroni-adjusted pairwise comparisons $(\mathrm{p}<.008)$ were conducted with stress phase. Estimated marginal means based on log-transformed HF-HRV.

** $\mathrm{p}<001$.

${ }^{*} \mathrm{p}<.01$.

\section{Discussion}

This study examined HRV during conditions of baseline, stress, and post-stress mindfulness meditation versus rest in Perfectionists and Controls. As predicted, the Control participants responded to the audio-instructed mindfulness meditation condition with higher levels of HRV compared to the audio-description rest condition. This difference had a large effect size and appears to demonstrate the effectiveness of mindfulness in promoting relaxation after a cognitive stressinduction. Importantly, the lack of a significant response by Perfectionists to the meditation condition raises questions about the psychophysiological dynamics of perfectionism in relation to mindfulness effects.

In a recent controlled experiment on mindfulness meditation that used cardiac measures, Zeidan et al. (2010) studied 82 undergraduates with no meditation experience in a design comparing traditional meditation training with a sham condition. The sham condition lacked the essential instructions of mindfulness (i.e. awareness of breathing sensations) yet included verbal cues suggestive of meditative experiences. The study reported greater decreases in distressed mood and HR following the meditation condition compared to the sham condition (Zeidan et al., 2010). The present study extends this research by observing a stress phase prior to randomizing novice meditators to a mindfulness instruction or a mindfulness description condition. The inclusion of a stress condition eliciting a sympathetic reaction permitted the study

Table 3

Means (SEM) of HF-HRV in conditions according to post-stress phases within groups.

\begin{tabular}{|c|c|c|c|c|c|}
\hline \multicolumn{3}{|c|}{ Maladaptive perfectionists $(n=21)$} & \multicolumn{3}{|c|}{ Controls $(n=39)$} \\
\hline Phase & $\begin{array}{l}\text { Meditation } \\
(n=12)\end{array}$ & $\begin{array}{l}\text { Rest } \\
(n=9)\end{array}$ & $\begin{array}{l}\text { Meditation } \\
(n=19)\end{array}$ & $\begin{array}{l}\text { Rest } \\
(n=20)\end{array}$ & $\overline{\text { p value }^{\mathrm{a}}}$ \\
\hline $\begin{array}{l}\text { Post-stress } \\
1-5 \mathrm{~min}\end{array}$ & $2.92(.11)$ & $2.75(.13)$ & $3.27(.09)$ & $2.66(.09)$ & $<.000$ \\
\hline $\begin{array}{l}\text { Post-stress } \\
6-10 \mathrm{~min}\end{array}$ & $2.87(.10)$ & $2.76(.11)$ & $3.11(.08)$ & $2.72(.08)$ & .001 \\
\hline
\end{tabular}

Note. Estimated marginal means based on log-transformed HF-HRV and adjusted with covariate resting HF-HRV. Standard errors of the mean in brackets.

a Based on univariate $F$ tests for simple effects of condition. 
of relaxation using HRV to measure changes in parasympathetic function. The present finding of enhanced HRV during mindfulness meditation in Controls is consistent with recent research (Burg and Wolf, 2012; Krygier et al., 2013), and suggests that some predisposition to stressful cognitions (i.e. perfectionism) may hinder the effectiveness of brief mindfulness meditation treatments.

The 'perseverative cognition' model, which describes the role of worry and rumination in activating, and elongating, the stress response (Brosschot et al., 2006; Brosschot, 2010), may explain why meditation effects were not present in Perfectionists. The stress-induction task included a self-evaluative component by providing immediate feedback of each trial response ("Right Answer" or "Wrong Answer") and total correct and incorrect responses up to the current trial. Given the Perfectionists' higher tendency for perfectionist (i.e. self-evaluative) cognitions, they might have been more susceptible to the 'perseverative' stress response during meditation practice, due to ruminations about the prior task performance or worry about implementing the meditation instructions. Furthermore, in specifically studying cardiovascular stress responses to tasks with self-evaluative components, Gendolla et al. (2008) found greater systolic blood pressure reactivity during high self-focus conditions with participants exposed to their own facial expressions in a monitor amidst performance. This finding was consistent across tasks with varying difficulty (unfixed, difficult, extreme) (Gendolla et al., 2008) and suggests that in an achievement context, an element of self-focused feedback can be a hindrance to cardiovascular regulation. The current study's mindfulness instructions did not explicitly reference the task performance, however, the instructions to relax and become aware of one's thoughts necessitate a self-focus that may have resulted in the hindrance to cardiac function observed in the Perfectionists. With regards to the attentional content during mindfulness meditation, this raises question about how self-focused attention may relate to the expected relaxation effects.

Regulating attention towards distressing cognitions and emotions is a coping strategy taught to distressed individuals in current therapeutic paradigms such as Mindfulness-Based Stress Reduction (Nyklǐček et al., 2013) and acceptance and commitment therapy (Hayes et al., 2006). However, there is little psychophysiological evidence for the effectiveness of attention regulation in modulating the stress response. Only one published study (Healy, 2010) has investigated the relationship between attention regulation and HRV in the context of stress. This study found that students reporting low levels of attentional control displayed lower resting HRV and self-reported higher levels of anxiety (Healy, 2010). Attentional difficulties after a period of cognitive stress may explain why, in the present study, Perfectionists did not demonstrate a substantial HRV increase when exposed to brief mindfulness training. When contrasted with the Control's response, the lack of HRV increase in Perfectionists during mindfulness meditation is suggestive of a maladaptive response to what is typically a relaxation-inducing practice (Grossman et al., 2004).

One explanation for this response may be that in attending to perfectionist cognitions, Perfectionists are avoiding somatic, stress-related sensations. According to Santanello and Gardner (2006), the relationship between maladaptive perfectionism and worry is partially mediated by experiential avoidance-the tendency to avoid attention towards undesirable sensations, emotions, and thoughts. The requirement of implementing the mindfulness instructions may have been interpreted as a cognitive challenge and provoked perfectionistic cognitions, which in turn, led to avoiding rather than attending to the experiential qualities of distress (Bardeen et al., 2013; Santanello and Gardner, 2006). The question of whether the lack of HRV increase in Perfectionists is due to inherent physiological incapability or to the attention regulation difficulties still remains. Nonetheless, it appears Perfectionists did not demonstrate the enhanced vagal tone achieved by Controls attributed to attention on the mindfulness meditation instructions of breathing awareness and nonjudgmental observation of thoughts, emotions, and sensations. Given this result, future research should focus explicitly on the instructional features of mindfulness meditation (including the nature, amount, and duration of instructions) and the factors that affect their successful implementation by both distressed personality types and novice meditators.

The results of the present study do not support the hypothesis of a group effect on HRV, as Perfectionists did not exhibit a significantly lower HRV than controls during stress. Of further note is that the Control group showed a trend towards decreased HRV from baseline to stress, whereas Perfectionists did not (Fig. 2). Recent research on the Big Five personality variables has found that individuals high on neuroticism and low on agreeableness exhibit blunted stress reactivity based on measures of salivary cortisol, HR, and blood pressure (Bibbey et al., 2013). The current HRV-based stress assessment raises questions about the possibility of Perfectionists exhibiting a similarly blunted stress reactivity as seen with other distressed personality factors. The lack of a substantial stress response in Perfectionists compared to Controls might indicate a perpetual withdrawal of vagal tone resulting from continuous encounters with perfectionistic stress. Afterwards, in post-stress rest conditions, Perfectionists and Controls exhibited similar HRV (Fig. 2), which does not reflect the tendency for an elongated stress response in Perfectionists as previously speculated. For the purposes of studying the ability to return to resting cardiac levels (without active coping practices) it would be advisable to use longer durations of post-stress assessment.

Previous attempts to examine HRV during mindfulness meditation have observed increases in the high-frequency band $(0.15-0.4 \mathrm{~Hz})$, the most approximate estimate of parasympathetic function and, thereby, respiration-based vagal activity (Allen et al., 2007; Force, 1996). In a recent investigation measuring HRV during meditation after participants had attended a 10-day Vipassana meditation retreat, Krygier et al. (2013) found a significant increase in high frequency HRV during mindfulness meditation compared to resting baseline with a large effect size. In the present study, a significant HRV increase in Controls during post-stress mindfulness meditation with a large effect size compliments the previous finding. Importantly, the simple effect of Condition for Controls was highly significant (Table 3 ) with a similarly large effect size. This pattern may suggest that a different physiological response was evident at the levels of group and post-stress conditions, and supports the potential for HRV to be an important physiological correlate of cognitively stressed and mindful states.

The present study has several limitations. The practical significance of a short term stress response is questionable, particularly as the stress-induction (pattern recognition task) in this study was newly designed and has not been validated. While the task achieved the goal of evoking a stress response as supported by significant HRV decreases, the verbal performance ratings did not indicate significant differences between Perfectionists and Controls (Table 1). In other words, Perfectionists did not report perceiving greater failure after the stressinduction compared to Controls. This combined with comparable HRV measures during the stress phase for Perfectionists and Controls (Fig. 2) make it difficult to determine whether there are substantial differences in (subjectively perceived) stress levels. This indicates a need to operationalize perfectionism for use in future studies to determine whether normative stress and perfectionistic stress could have differing effects on HRV.

These findings must be conservatively interpreted as they are only generalizable to undergraduate populations. Recruitment through a credit system predicated on research participation indicates reliance on a convenience sample. On this note, future studies focusing on perfectionism should consider using multiple dimensions to classify Perfectionists, particularly as the personality construct is further conceptualized in the clinical context (Shafran et al., 2003). The current study utilized a screening procedure which resulted in uneven sample sizes of Perfectionists $(\mathrm{N}=21)$ and Controls $(\mathrm{N}=39)$, and also necessitated the analysis to be conducted on a non-clinical, categorical group variable. In defense of this approach, it is important to note that the PCI 
has reliably differentiated populations requiring clinical intervention such as individuals with lowered self-esteem, anxiety, and depressive disorder (Arpin-Cribbie et al., 2008; Arpin-Cribbie et al., 2012; Flett et al., 2007; Flett et al., 1995). Furthermore, the PCI has been employed in multiple randomized-controlled trials which have demonstrated that Perfectionists can achieve benefits in depressed and anxious moods (Radhu et al., 2012a) as well as cortical inhibition (Radhu et al., 2012b), by way of cognitive-behavioral therapy and mindfulness practice. Furthermore, the uneven proportion in this study is representative of the typical prevalence found at this university, in which a previous recruit of $\mathrm{N}=992$ participants yielded $\mathrm{N}=248(\sim 25 \%)$ maladaptive perfectionists with the same screening procedure (Pirbaglou et al., 2013).

In spite of the above limitations, the present study improved on various aspects of previous attempts of assessing HRV during mindfulness meditation. Firstly, as suggested by Zeidan et al. (2010), the inclusion of stress-induction prior to randomization to mindfulness meditation or a rest condition helped show the benefits of brief mindfulness training after the experience of stress. Secondly, the lack of adequate control conditions in meditation research has been a source of criticism (Toneatto and Nguyen, 2007). The use of an identically structured rest condition featuring an audio-stimuli description of mindfulness meditation demonstrates a novel and effective approach to controlling for brief mindfulness practice in novice meditators. This corresponds to the approach taken in studies of Mindfulness-Based Stress Reduction (MBSR), wherein an active control condition, Health Enhancement Program, involves health education (e.g. nutrition, chronic disease) but does not feature any specific mindfulness training (MacCoon et al., 2012; Rosenkranz et al., 2013). Finally, the focus on maladaptive perfectionists demonstrated the viability of including personality factors to assess psychopathological risks with consideration for attention regulation capabilities. Future psychophysiological research may consider stratifying samples with greater clinical implications such as depressive or anxious personality styles.

\section{Conclusion}

The effects of maladaptive perfectionism and mindfulness meditation on HRV were found to be consistent with expectations in this study. After a stress procedure, only Controls randomized to the mindfulness meditation condition exhibited a significant HRV increase, while neither Perfectionist meditators nor non-meditators exhibited substantial HRV elevations. Further testing revealed HRV was significantly elevated during meditation compared to post-stress rest in the Controls but not Perfectionists. These findings suggest that brief mindfulness practice is conducive to post-stress relaxation, whereas relaxation is hindered in the context of perfectionistic stress. This finding can prove useful in designing mindfulness-based therapeutic interventions for individuals prone to maladaptive perfectionism and other, non-clinically defined but, nonetheless, high stress conditions. If additional research demonstrates a strong relationship between HRV and mindfulness, then HRV may be used to index improvement in attention regulation and, thereby, progress made through a therapeutic intervention. It is hoped that the potential of studying psychological processes such as perfectionism and mindfulness through autonomic physiological variables will stimulate increased interdisciplinary research in this area.

\section{Conflict of interest}

The authors have no conflicts of interest: they have no financial or personal relationships with other people or organizations that could inappropriately influence their work.

\section{Acknowledgments}

The authors gratefully acknowledge the assistance of all persons and volunteers whose participation was essential in the successful completion of the study. The authors would also like to thank Professor John B. Allen for his advice on HRV analysis, and the Statistical Consulting Service offered by the Institute for Social Research at York University. Joel Katz is supported by a Canadian Institutes of Health Research Canada Research Chair in Health Psychology.

\section{References}

Allen, J.J.B., Chambers, A.S., Towers, D.N., 2007. The many metrics of cardiac chronotropy: a pragmatic primer and a brief comparison of metrics. Biol. Psychol. 74 (2), 243-262. http://dx.doi.org/10.1016/j.biopsycho.2006.08.005.

Antony, M.M., Purdon, C.L., Huta, V., Swinson, R.P., 1998. Dimensions of perfectionism across the anxiety disorders. Behav. Res. Ther. 36 (12), 1143-1154 (Retrieved from http://www.ncbi.nlm.nih.gov/pubmed/9745799).

Argus, G., Thompson, M., 2007. Perceived social problem solving, perfectionism, and mindful awareness in clinical depression: an exploratory study. Cogn. Ther. Res. 32 (6), 745-757. http://dx.doi.org/10.1007/s10608-006-9102-1.

Arpin-Cribbie, C., Irvine, J., Ritvo, P., Cribbie, R., Flett, G.L., Hewitt, P.L., 2008. Perfectionism and psychological distress: a modeling approach to understanding their therapeutic relationship. J. Ration. Emot. Cogn. Behav. Ther. 26 (3), 151-167. http://dx.doi.org/ 10.1007/s10942-007-0065-2.

Arpin-Cribbie, C., Irvine, J., Ritvo, P., 2012. Web-based cognitive-behavioral therapy for perfectionism: a randomized controlled trial. Psychother. Res. J. Soc. Psychother. Res. 22 (2), 194-207. http://dx.doi.org/10.1080/10503307.2011.637242.

Ashby, J., Noble, C., Gnilka, P., 2012. Multidimensional perfectionism, depression, and satisfaction with life: differences among perfectionists and tests of a stress-mediation model. J. Coll. Couns. 15, 130-143.

Bardeen, J.R., Fergus, T.A., Orcutt, H.K., 2013. Experiential avoidance as a moderator of the relationship between anxiety sensitivity and perceived stress. Behav. Ther. 44 (3), 459-469. http://dx.doi.org/10.1016/j.beth.2013.04.001.

Bibbey, A., Carroll, D., Roseboom, T.J., Phillips, A.C., de Rooij, S.R., 2013. Personality and physiological reactions to acute psychological stress. Int. J. Psychophysiol. 90 (1), 28-36. http://dx.doi.org/10.1016/j.ijpsycho.2012.10.018.

Brosschot, J.F., 2010. Markers of chronic stress: prolonged physiological activation and (un)conscious perseverative cognition. Neurosci. Biobehav. Rev. 35 (1), 46-50. http://dx.doi.org/10.1016/j.neubiorev.2010.01.004.

Brosschot, J.F., Dijk, E. Van, Thayer, J.F., 2007. Daily worry is related to low heart rate variability during waking and the subsequent nocturnal sleep period. Int. J. Psychophysiol. 63, 39-47. http://dx.doi.org/10.1016/j.ijpsycho.2006.07.016.

Brosschot, J.F., Gerin, W., Thayer, J.F., 2006. The perseverative cognition hypothesis: a review of worry, prolonged stress-related physiological activation, and health. J. Psychosom. Res. 60 (2), 113-124. http://dx.doi.org/10.1016/j.jpsychores.2005.06. 074

Brosschot, J.F., Thayer, J.F., 2003. Heart rate response is longer after negative emotions than after positive emotions. Int. J. Psychophysiol. 50 (3), 181-187. http://dx.doi. org/10.1016/S0167-8760(03)00146-6.

Burg, J.M., Wolf, O.T., 2012. Mindfulness as self-regulated attention. Swiss J. Psychol. 71 (3), 135-139. http://dx.doi.org/10.1024/1421-0185/a000080.

Cacioppo, J.T., Tassinary, L.G., Bernston, G.G., 2007. Handbook of Psychophysiology. 3rd ed. Cambridge University Press, New York, NY.

Chalmers, J. a, Quintana, D.S., Abbott, M.J.-A., Kemp, A.H., 2014. Anxiety disorders are associated with reduced heart rate variability: a meta-analysis. Front. Psychol. 5, 80. http://dx.doi.org/10.3389/fpsyt.2014.00080 (July).

Chang, E.C., Sanna, L.J., 2001. Negative attributional style as a moderator of the link between perfectionism and depressive symptoms: preliminary evidence for an integrative model. J. Couns. Psychol. 48 (4), 490-495. http://dx.doi.org/10.1037//00220167.48.4.490.

Chida, Y., Steptoe, A., 2010. Greater cardiovascular responses to laboratory mental stress are associated with poor subsequent cardiovascular risk status: a meta-analysis of prospective evidence. Hypertension 55 (4), 1026-1032. http://dx.doi.org/10.1161/ HYPERTENSIONAHA.109.146621.

Chiesa, A., Calati, R., Serretti, A., 2011. Does mindfulness training improve cognitive abilities? A systematic review of neuropsychological findings. Clin. Psychol. Rev. 31 (3), 449-464. http://dx.doi.org/10.1016/j.cpr.2010.11.003

Delgado, L.C., Guerra, P., Perakakis, P., Vera, M.N., del Paso, G.R., Vila, J., 2010. Treating chronic worry: psychological and physiological effects of a training programme based on mindfulness. Behav. Res. Ther. 48 (9), 873-882. http://dx.doi.org/10.1016/ j.brat.2010.05.012

Delgado-pastor, L.C., Perakakis, P., Subramanya, P., Telles, S., Vila, J., 2013. Mindfulness (Vipassana) meditation : effects on P3b event-related potential and heart rate variability. Int. J. Psychophysiol. 90 (2), 207-214. http://dx.doi.org/10.1016/j. ijpsycho.2013.07.006.

Didonna, F., 2009. In: Didonna, F. (Ed.), Clinical Handbook of Mindfulness. Springer New York, New York, NY http://dx.doi.org/10.1007/978-0-387-09593-6.

Ditto, B., Eclache, M., Goldman, N., 2006. Short-term autonomic and cardiovascular effects of mindfulness body scan meditation. Ann. Behav. Med. Publ. Soc. Behav. Med. 32, 227-234 (Retrieved from http://www.ncbi.nlm.nih.gov/pubmed/17107296).

Fabes, R., Eisenberg, N., 1997. Regulatory control and adult's stress-related responses to daily events. J. Pers. Soc. Psychol. 73 (5), 1107-1117.

Flett, G., Hewitt, P., Blanestein, K., Gray, L., 1998. Psychological distress and the frequency of perfectionistic thinking. J. Pers. Soc. Psychol. 75 (5), 1363-1381 (Retrieved from http://www.ncbi.nlm.nih.gov/pubmed/9866193).

Flett, G., Hewitt, P., Whelan, T., Martin, T.R., 2007. The perfectionism cognitions inventory: psychometric properties and associations with distress and deficits in cognitive self- 
management. J. Ration. Emot. Cogn. Behav. Ther. 25 (4), 255-277. http://dx.doi.org/ 10.1007/s10942-007-0055-4.

Flett, G.L., Hewitt, P.L., Blankenstein, K.R., Mosher, S.W., 1995. Perfectionism, life events, and depressive symptoms: a test of a diathesis-stress model. Curr. Psychol. 14, 112-137.

Flett, G.L., Hewitt, P.L., Demerjian, A., Sturman, E.D., Sherry, S.B., Cheng, W., 2011. Perfectionistic automatic thoughts and psychological distress in adolescents: an analysis of the perfectionism cognitions inventory. J. Ration. Emot. Cogn. Behav. Ther. 30 (2), 91-104. http://dx.doi.org/10.1007/s10942-011-0131-7.

Force, T., 1996. Guidelines heart rate variability. Eur. Heart J. 17, 354-381.

Gendolla, G.H.E., Richter, M., Silvia, P., 2008. Self-focus and task difficult effects on effortrelated cardiovascular reactivity. Psychophysiology 45, 653-662.

Glynn, L.M., 2002. The role of rumination in recovery from reactivity: cardiovascular consequences of emotional states. Psychosom. Med. 64 (5), 714-726. http://dx.doi.org/ 10.1097/01.PSY.0000031574.42041.23.

Grossman, P., Heidenreich, T., Michalak, J., 2004. Mindfulness practice: a unique clinical intervention for the behavioral sciences. Mindfulness Acceptance Psychother. 16-18.

Grossman, P., Taylor, E.W., 2007. Toward understanding respiratory sinus arrhythmia: relations to cardiac vagal tone, evolution and biobehavioral functions. Biol. Psychol. 74 (2), 263-285. http://dx.doi.org/10.1016/j.biopsycho.2005.11.014.

Guglietti, C.L., Daskalakis, Z.J., Radhu, N., Fitzgerald, P.B., Ritvo, P., 2013. Meditation-related increases in GABAB modulated cortical inhibition. Brain Stimul. 6 (3), 397-402. http://dx.doi.org/10.1016/j.brs.2012.08.005.

Haensel, A., Mills, P.J., Nelesen, R. a, Ziegler, M.G., Dimsdale, J.E., 2008. The relationship between heart rate variability and inflammatory markers in cardiovascular diseases. Psychoneuroendocrinology 33 (10), 1305-1312. http://dx.doi.org/10.1016/j. psyneuen.2008.08.007.

Harris, P.W., Pepper, C.M., Maack, D.J., 2008. The relationship between maladaptive perfectionism and depressive symptoms: the mediating role of rumination. Personal. Individ. Differ. 44, 150-160. http://dx.doi.org/10.1016/j.paid.2007.07.011.

Hayes, S.C., Luoma, J.B., Bond, F.W., Masuda, A., Lillis, J., 2006. Acceptance and commitment therapy: model, processes and outcomes. Behav. Res. Ther. 44 (1), 1-25 (Retrieved from http://eprints.gold.ac.uk/506/).

Healy, B., 2010. The effect of attentional control and heart-period variability on negative affect and trait anxiety. J. Gen. Psychol. 137 (2), 140-150. http://dx.doi.org/10.1080 00221301003645079

Hewitt, P., Flett, G., Turnbull-Donovan, W., Mikail, S., 1991. The multidimensional perfectionism scale: reliability, validity, and psychometric properties in psychiatric samples. Psychol. Assess. 3 (3), 464-468. http://dx.doi.org/10.1037//1040-3590.3.3.464.

Hewitt, P.L., Flett, G.L., 1991. Perfectionism in the self and social contexts: conceptualization, assessment, and association with psychopathology. J. Pers. Soc. Psychol. 60 (3), 456-470 (Retrieved from http://www.ncbi.nlm.nih.gov/pubmed/2027080).

Houtveen, J.H. Rietveld, S de Geus, EJ.C. 2002. Contribution of tonic vagal modulation of heart rate, central respiratory drive, respiratory depth, and respiratory frequency to respiratory sinus arrhythmia during mental stress and physical exercise. Psychophysiology 39 (4), 427-436. http://dx.doi.org/10.1017/S0048577202394022.

Karim, N., Hasan, J.A., Ali, S.S., 2011. Heart rate variability - a review. J. Basic Appl. Sci. 7 (1), 71-77.

Kemp, A.H., Quintana, D.S., Felmingham, K.L., Matthews, S., Jelinek, H.F., 2012. Depression, comorbid anxiety disorders, and heart rate variability in physically healthy, unmedicated patients: implications for cardiovascular risk. PLoS ONE 7 (2), e30777. http:// dx.doi.org/10.1371/journal.pone.0030777.

Krygier, J.R., Heathers, J. a J., Shahrestani, S., Abbott, M., Gross, J.J., Kemp, A.H., 2013. Mindfulness meditation, well-being, and heart rate variability: a preliminary investigation into the impact of intensive Vipassana meditation. Int. J. Psychophysiol. Off. J. Int. Organ. Psychophysiol. http://dx.doi.org/10.1016/j.ijpsycho.2013.06.017.

Lazar, S.W., Kerr, C.E., Wasserman, R.H., Gray, J.R., Douglas, N., Treadway, M.T., ..., Dusek J.A., 2006. Meditation experience is associated with increased cortical thickness. Neuroreport 16 (17), 1893-1897.

Lo, A., Abbott, M.J., 2013. Review of the theoretical, empirical, and clinical status of adaptive and maladaptive perfectionism. Behav. Chang. 30 (02), 96-116. http://dx.doi. $\operatorname{org} / 10.1017 /$ bec.2013.9.

Lutz, A., Slagter, H.A., Dunne, J.D., Davidson, R.J., 2008. Attention regulation and monitoring in meditation. Trends Cogn. Sci. 12 (4), 163-169. http://dx.doi.org/10.1016/j.tics. 2008.01.005.

MacCoon, D.G., Imel, Z.E., Rosenkranz, M.A., Sheftel, J.G., Weng, H.Y., Sullivan, J.C., ..., Lutz, A., 2012. The validation of an active control intervention for Mindfulness Based Stress Reduction (MBSR). Behav. Res. Ther. 50 (1), 3-12. http://dx.doi.org/10.1016/j.brat. 2011.10.011

Mankus, A.M., Aldao, A., Kerns, C., Mayville, E.W., Mennin, D.S., 2013. Mindfulness and heart rate variability in individuals with high and low generalized anxiety symptoms. Behav. Res. Ther. 51 (7), 386-391. http://dx.doi.org/10.1016/j.brat.2013.03.005.

Marano, G., Harnic, D., Lotrionte, M., Biondi-Zoccai, G., Abbate, A., Romagnoli, E., Mazza, M., 2009. Depression and the cardiovascular system: increasing evidence of a link and therapeutic implications. Expert. Rev. Cardiovasc. Ther. 7 (9), 1123-1147. http://dx.doi.org/10.1586/erc.09.78.

Masuda, A., Tully, E.C., 2012. The role of mindfulness and psychological flexibility in somatization, depression, anxiety, and general psychological distress in a nonclinical college sample. J. Evid.-Based. Complement. Altern. Med. 17.

Miu, A.C., Heilman, R.M., Miclea, M., 2009. Reduced heart rate variability and vagal tone in anxiety: trait versus state, and the effects of autogenic training. Auton. Neurosci. Basic Clin. 145 (1-2), 99-103. http://dx.doi.org/10.1016/j.autneu.2008.11.010.
Nyklíček, I., Mommersteeg, P.M.C., Van Beugen, S., Ramakers, C., Van Boxtel, G.J., 2013. Mindfulness-based stress reduction and physiological activity during acute stress: a randomized controlled trial. Health Psychol. http://dx.doi.org/10.1037/a0032200.

Papousek, I., Paechter, M., Lackner, H.K., 2011. Delayed psychophysiological recovery after self-concept-inconsistent negative performance feedback. Int. J. Psychophysiol. 82 (3), 275-282. http://dx.doi.org/10.1016/j.ijpsycho.2011.09.013.

Phongsuphap, S., Pongsupap, Y., Chandanamattha, P., Lursinsap, C., 2008. Changes in heart rate variability during concentration meditation. Int. J. Cardiol. 130 (3), 481-484. http://dx.doi.org/10.1016/j.ijcard.2007.06.103.

Pieper, S., Brosschot, J.F., van der Leeden, R., Thayer, J.F., 2007. Cardiac effects of momentary assessed worry episodes and stressful events. Psychosom. Med. 69, 901-909. http://dx.doi.org/10.1097/PSY.0b013e31815a9230.

Pieper, S., Brosschot, J.F., van der Leeden, R., Thayer, J.F., 2010. Prolonged cardiac effects of momentary assessed stressful events and worry episodes. Psychosom. Med. 72, 570-577. http://dx.doi.org/10.1097/PSY.0b013e3181dbc0e9.

Pirbaglou, M., Cribbie, R., Irvine, J., Radhu, N., Vora, K., Ritvo, P., 2013. Perfectionism, anxiety, and depressive distress: evidence for the mediating role of negative automatic thoughts and anxiety sensitivity. J. Am. Coll. Heal. 61 (8), 477-483. http://dx.doi org/10.1080/07448481.2013.833932.

Porges, S.W., Byrne, E.A., 1992. Research methods for measurement of heart rate and respiration. Biol. Psychol. 34, 93-130. http://dx.doi.org/10.1016/0301-0511(92)90012-J.

Radhu, N., Daskalakis, Z.J., Arpin-Cribbie, C.A., Irvine, J., Ritvo, P., 2012a. Evaluating a webbased cognitive-behavioral therapy for maladaptive perfectionism in university students. J. Am. Coll. Heal. 60 (5), 357-366. http://dx.doi.org/10.1080/07448481.2011. 630703.

Radhu, N., Daskalakis, Z.J., Guglietti, C.L., Farzan, F., Barr, M.S., Arpin-Cribbie, C.A., ..., Ritvo P., 2012b. Cognitive behavioral therapy-related increases in cortical inhibition in problematic perfectionists. Brain Stimul. 5 (1), 44-54. http://dx.doi.org/10.1016/j. brs.2011.01.006

Ritvo, P., Vora, K., Irvine, J., Mongrain, M., Azargive, S., Azam, M., ..., Cribbie, R., 2013 Reductions in negative automatic thoughts in students attending mindfulness tutorials predicts increased life satisfaction. Int. J. Educ. Psychol. 2 (3), 272-296. http://dx.doi.org/10.4471/ijep.2013.28.

Rosenkranz, M., Davidson, R.J., Maccoon, D.G., Sheridan, J.F., Kalin, N.H., Lutz, A., 2013. A comparison of mindfulness-based stress reduction and an active control in modulation of neurogenic inflammation. Brain Behav. Immun. 27 (1), 174-184. http://dx. doi.org/10.1016/j.bbi.2012.10.013.

Saboonchi, F., Lundh, L., 1997. Perfectionism, self-consciousness, and anxiety. Personal. Individ. Differ. 22 (6), 921-928.

Santanello, A.W., Gardner, F.L., 2006. The role of experiential avoidance in the relationship between maladaptive perfectionism and worry. Cogn. Ther. Res. 31 (3), 319-332. http://dx.doi.org/10.1007/s10608-006-9000-6.

Segerstrom, S.C., Nes, L.S., 2007. Heart rate variability reflects self-regulatory strength, effort, and fatigue. Psychol. Sci. 18 (3), 275-281.

Shafran, R., Cooper, Z., Fairburn, C.G., 2003. "Clinical perfectionism" is not "multidimensional perfectionism": a reply to Hewitt, Flett, Besser, Sherry \& McGee. Behav. Res. Ther. 41 (10), 1217-1220. http://dx.doi.org/10.1016/S0005-7967(03)00020-2.

Short, M.M., Mazmanian, D., 2013. Perfectionism and negative repetitive thoughts: examining a multiple mediator model in relation to mindfulness. Personal. Individ. Differ. 55 (6), 716-721. http://dx.doi.org/10.1016/j.paid.2013.05.026.

Taelman, J., Vandeput, S., Spaepen, A., Huffel, S. Van, 2009. Influence of mental stress on heart rate and heart rate variability. The International Federation for Medical and Biological Engineering. Springer-Verlag, Berlin, pp. 1366-1369.

Takahashi, T., Murata, T., Hamada, T., Omori, M., Kosaka, H., Kikuchi, M., ..., Wada, Y. 2005. Changes in EEG and autonomic nervous activity during meditation and their association with personality traits. Int. J. Psychophysiol. 55 (2), 199-207. http://dx doi.org/10.1016/j.ijpsycho.2004.07.004.

Tang, Y.-Y., Ma, Y., Fan, Y., Feng, H., Wang, J., Feng, S., ..., Fan, M., 2009. Central and autonomic nervous system interaction is altered by short-term meditation. Proc. Natl. Acad. Sci. U. S. A. 106 (22), 8865-8870. http://dx.doi.org/10.1073/pnas.0904031106,

Thayer, J.F., Ahs, F., Fredrikson, M., Sollers, J.J., Wager, T.D., 2012. A meta-analysis of heart rate variability and neuroimaging studies: implications for heart rate variability as a marker of stress and health. Neurosci. Biobehav. Rev. 36 (2), 747-756. http://dx. doi.org/10.1016/j.neubiorev.2011.11.009.

Thayer, J.F., Hansen, A.L., Saus-Rose, E., Johnsen, B.H., 2009. Heart rate variability, prefrontal neural function, and cognitive performance: the neurovisceral integration perspective on self-regulation, adaptation, and health. Ann. Behav. Med. 37 (2) 141-153. http://dx.doi.org/10.1007/s12160-009-9101-z.

Toneatto, T., Nguyen, L., 2007. Does mindfulness meditation improve anxiety and mood symptoms? A review of the controlled research. Can. J. Psychiatry 52 (4), 260-266 (Retrieved from http://www.ncbi.nlm.nih.gov/pubmed/17500308).

Verkuil, B., Brosschot, J.F., de Beurs, D.P., Thayer, J.F., 2009. Effects of explicit and implicit perseverative cognition on cardiac recovery after cognitive stress. Int. J. Psychophysiol. 74 (3), 220-228. http://dx.doi.org/10.1016/j.jpsycho.2009.09.003.

Zeidan, F., Johnson, S.K., Gordon, N.S., Goolkasian, P., 2010. Effects of brief and sham mindfulness meditation on mood and cardiovascular variables. J. Altern. Complement. Med. N. Y. 16, 867-873 Retrieved from http://www.ncbi.nlm.nih.gov/pubmed/ 20666590. 